\section{Drawbacks of peer review}

SIR - All reputable learned journals employ the peer-review system to help to decide on publication or rejection of submitted articles. Thus the system can be viewed as a method for evaluating the quality of potential publications. Every scientific method should be validated before it is generally used. One essential step in this validation is the assessment of the method's reproducibility. We have attempted to define the reproducibility of the peer-review method.

Copies of one paper submitted to a medical journal were sent simultaneously the whole range. The paper sent out for review was by no means on a controversial subject. The results therefore suggest that the method of evaluating scientific papers by peer review is unreliable and open to bias and should itself be submitted to evaluation.

Since acceptance or rejection of a paper nowadays strongly influences the career of the authors, the poor reproducibility is a cause for concern. One would therefore hope for an improvement of the method. A system incorporating regular, blind tests concerning the quality of the review-
Descriptive statistics for each quality criterion

\begin{tabular}{|c|c|c|c|c|c|c|c|}
\hline \multicolumn{8}{|c|}{ Frequency of ratings } \\
\hline & $\underset{(1)}{U}$ & $\begin{array}{l}A \\
(2)\end{array}$ & $\begin{array}{l}F \\
(3)\end{array}$ & $\begin{array}{c}G \\
(4)\end{array}$ & $\begin{array}{c}E \\
(5)\end{array}$ & $q 1$ & $q^{3}$ \\
\hline Scientific merit & 2 & 3 & 7 & 14 & 5 & 3.00 & 4.00 \\
\hline $\begin{array}{l}\text { Clarity of } \\
\text { description }\end{array}$ & 1 & 0 & 6 & 15 & 8 & 3.75 & 5.00 \\
\hline $\begin{array}{l}\text { Statistical } \\
\text { methods }\end{array}$ & 4 & 2 & 7 & 11 & 7 & 3.00 & 4.00 \\
\hline Methodology & 2 & 0 & 5 & 17 & 6 & 3.75 & 4.00 \\
\hline References & 0 & 2 & 2 & 15 & 11 & 4.00 & 5.00 \\
\hline $\begin{array}{l}\text { Quality of tables/ } \\
\text { figures }\end{array}$ & 0 & 1 & 10 & 16 & 3 & 3.00 & 4.00 \\
\hline Discussion & 1 & 3 & 8 & 13 & 5 & 3.00 & 4.00 \\
\hline Linguistic merit & 0 & 1 & 6 & 16 & 7 & 3.75 & 4.25 \\
\hline $\begin{array}{l}\text { Overall } \\
\text { judgement }\end{array}$ & 2 & 2 & 4 & 16 & 5 & 3.00 & 4.00 \\
\hline
\end{tabular}

U, unacceptable (1); A, acceptable (2), F, fair (3); G, good (4); E, excellent (5).

$q 1=25 \%$ percentile (first quartile), q $3=75 \%$ percentile (third quartile) median and mode for all criteria: 4 (frequencies of median and mode are printed in bold)

to 45 experts, all of them members of editorial boards of journals relating to the subject of the submitted paper. They were asked to express their opinion of the paper on the journal's standard questionnaire judging 8 quality criteria on a numerical scale from 5 (excellent) to 1 (unacceptable). In addition, an overall judgement of the paper had to be indicated on the same scale. No reviewer was told that he or she was being tested. Thirty-one adequately filled forms were received back; 14 potential reviewers declined because they claimed to be not fully competent or had too little time to do the work within the deadline. On the basis of the individual ratings, the reproducibility was estimated by calculating descriptive statistics for each item. The results are depicted in Table 1.

They demonstrate disappointingly poor reproducibility with extreme judgements ranging from 'unacceptable' to 'excellent' for most criteria. Even the criterion 'linguistic merit', which could have been expected to yield a fairly uniform judgement because the paper was written by two native English-speakers from the United Kingdom, was no exception. Similarly the overall judgement rating was spread over ers might exclude some sources of publication bias (1-3). The absence of reliability suggested by the present findings seems unacceptable for anyone aspiring to publish in peer-reviewed journals.

\section{E. Ernst}

\section{T. Saradeth}

K. L. Resch

Department of Physical Medicine and Rehabilitation,

University of Vienna,

Währinger Gürtel 18-20,

1090 Vienna, Austria

\section{Ernst, E. \& Kienbacher, T. Nature 352, 560 (1991) \\ 2. Wilmhurst, P. Lancet 337, 1419 (1991). \\ 3. Ernst, E. Resch, K. L. \& UUher, E. M. Ann. int. Med. 116. 958(1992).}

\section{HST still alive}

SIR - I am writing to correct the impression (Nature 362, 585; 1993) that the Hubble Space Telescope (HST) has not observed the recent bright supernova SN1993J in M81. Two separate observing programmes were initiated with HST within days of discovery of the supernova. The first observations with Hubble and the Goddard High Resolution Spectro- graph were obtained on 8 April and subsequent observations with the Faint Object Spectrograph were secured on 15 April.

The high resolution observations species superimposed on the spectrum of the supernova. The data are fabulous and reveal a wealth of information on the distribution of gas in our Galaxy and in M81. The lower resolution observations, which I have not seen, were taken to study spectral features in the supernova itself. I believe that they were successful.

The article in News and Views concludes with a discussion of nearby type I supernovae and gives the mistaken impression that no type I supernova has been near enough to give an unequivocal calibration of the distance scale.

Last year, Sandage and collaborators (Astrophys. J. 401, L7; 1992), using the Hubble Space Telescope, discovered and measured 27 Cepheid variables in the galaxy IC4182, thereby establishing a calibration for the type Ia supernova SN1937C. They report a Hubble constant of $51( \pm 10) \mathrm{km} \mathrm{s}^{-1} \mathrm{Mpc}^{-1}$.

\section{Chris Blades}

Space Telescope Science Institute, 3700 San Martin Drive,

Baltimore,

Maryland 21218, USA

$\square$ The important study by Sandage et al., valuable though it is, has not definitely resolved the question of Hubble's Constant. Editor, Nature.

\section{Aristotle's origins}

SIR - On the cover of the 7 January 1993 issue of Nature you refer to the Greek philosopher Aristotle as "Athenian philosopher and logician...". Aristotle was not from Athens. Acording to the Encyclopedia Britannica, he was born $(384 \mathrm{BC})$ and raised in the Greek colony of Stagira in Macedonia, northern Greece. Although he spent several years in Athens studying and teaching, he always remained a Macedonian. Indeed, he was forced to leave Athens shortly after the death of his student Alexander the Great $(323 \mathrm{BC})$, because of rising antiMacedonian sentiments in Athens ${ }^{2}$. Please notice that Macedonia, the largest province of Greece, is not to be confused with the pseudo-"Macedonian" state that emerged in 1991 after the break-up of Yugoslavia.

\section{George Phllippidis}

90 Corona Street,

Apt 1003,

Denver,

Colorado 80218, USA

Letters submitted for Correspondence should be typed, double-spaced, on one side of the paper only. 